\title{
New method of analysis of nitrofurans and nitrofuran metabolites in different biological matrices using UHPLC-MS/MS
}

\author{
Tomasz Śniegocki, Marta Giergiel, Bartosz Sell, Andrzej Posyniak \\ Department of Pharmacology and Toxicology, \\ National Veterinary Research Institute, 24-100 Pulawy, Poland \\ sniego@piwet.pulawy.pl
}

Received: February 21, $2018 \quad$ Accepted: June 11, 2018

\begin{abstract}
Introduction: The major difficulty in analysis of nitrofurans in feed, feed water, and food of animal origin is that nitrofurans have low molecular weights and fast metabolism. The principal goal of this study was to prepare a procedure for the determination of nitrofurans and their metabolites by a single method in different types of feed, feed water, and food of animal origin. Material and Methods: Two-gram samples were subjected to hydrolysis and derivatisation processes by addition of hydrochloric acid and 2-nitrobenzaldehyde. After incubation the sample was purified by solid phase extraction technique. Nitrofurans were analysed using ultra-high-pressure liquid chromatography-MS/MS (UHPLC-MS/MS). Results: The results of validation fulfil the requirement of the confirmatory criteria according to the European Commission Decision 2002/657/EC regarding apparent recoveries $(88.9 \%-107.3 \%)$, repeatability $(2.9 \%-9.4 \%)$ and within-laboratory reproducibility $(4.4 \%-10.7 \%)$. Conclusion: The method can be successfully applied to monitor nitrofurans and their metabolites in different matrices.
\end{abstract}

Keywords: nitrofurans, feed water, feed, food products, UHPLC-MS/MS.

\section{Introduction}

The use of nitrofurans has been banned in veterinary medicine within the European Union (Annex IV of Regulation 2377/90/EEC) because of their toxic influence on the health of consumers of animal origin food (4). Formerly, addition of nitrofurans to feeds or water was allowed in order to stimulate growth and in the prophylaxis and treatment of many bacterial and protozoan infections $(8,14)$.

In 1994, the EU prohibited the use of nitrofurans in veterinary medicine and no maximum residue limit (MRL) was established for these banned compounds due to safety not being possible to claim for any residue levels (4-6). However, the data from the Rapid Alert System for Food and Feed (RASFF) database for the years 2002 to 2017 showed 854 notification events reported for nitrofurans, indicating that contamination in various matrices is still present (12). The notifications referred to a wide range of products such as honey, feed and feed water, fish and aquaculture products, and meat and meat products (12).

Many methods have been created for analysis of nitrofuran metabolites in biological matrices $(8-11,14)$, but unfortunately only a few methods have been designed for determination of nitrofurans in feed water (1) and feed (2) using mass spectrometry techniques. Additionally, none of the existing methods could be used for determination of nitrofurans and nitrofuran metabolites in a single analytical procedure, which is why the purpose of this research was to create and validate such a procedure. This method for determination needs to fulfil the requirements of the confirmatory criteria according to European Commission Decision 2002/657/EC (4) and involves the solid-phase extraction (SPE) approach for confirmation and quantitation of residues of these compounds in biological matrices using ultra-high-pressure liquid chromatography-MS/MS (UHPLC-MS/MS). The aim of this research is elaboration of the first method for 
determination of nitrofurans and nitrofuran metabolites using UHPLC-MS/MS in a single analytical procedure.

\section{Material and Methods}

Materials. All reagents were of minimum analytical grade or higher. Materials were procured as previously described (13) or as follows: ethyl acetate, hexane (95\%), acetic acid (99\%), ammonium formate, and methanol (HPLC grade) were from J.T. Baker (the Netherlands). Ultrapure water was filtered through a Millipore Milli-Q system (USA). Nanosep MF $0.22 \mu \mathrm{m}$ filters were supplied by Pall (USA). Ammonia, 35\% hydrochloric acid, and anhydrous dipotassium hydrogen orthophosphate were obtained from POCH (Poland). Strata SDB-L SPE cartridges were products of Phenomenex (USA). Two-nitrobenzaldehyde (2-NBA), furazolidone, furaldatone, nitrofurantoin, nitrofurazone and their metabolites, 5-methylamorfolino-3-amino-2oxazolidone (AMOZ), 1-aminohydantoin (AHD), semicarbazide (SEM), 3-amino-2-oxazolidone (AOZ), and the internal standards 1,2-(15N2, 13C) SEM, AMOZ-d5, (3C13) AHD, and AOZ-d4 were purchased from the Sigma-Aldrich Chemical Company (Germany).

UHPLC-MS/MS. The UHPLC-MS/MS system consisted of an AB Sciex ExionLC UHPLC system connected to an AB Sciex API 5500 Qtrap mass spectrometer (AB Sciex, Canada). Analyst 1.6.3 software (AB Sciex) controlled the UHPLC-MS/MS system and Multiquant 3.2 (AB Sciex) was used to process the data. The MS/MS was operated as previously described with some modifications (10). Briefly, desolvation temperature was set at $500^{\circ} \mathrm{C}$, gas 1 (air) at 40 psi; gas 2 (air) at 40 psi; collision gas $\left(\mathrm{N}_{2}\right)$ to high; nebuliser gas $\left(\mathrm{N}_{2}\right)$ at 40 psi; and curtain gas $\left(\mathrm{N}_{2}\right)$ at 40 psi. The voltage of electron multiplier and the electrospray capillary were set at $2,100 \mathrm{~V}$ and 5,500 V, respectively. The chromatography was performed in a C8(2) column $3 \mu \mathrm{m} \times 2 \mathrm{~mm}, 75 \mathrm{~mm}$ (Phenomenex, USA), connected to a C8 precolumn $3 \mu \mathrm{m} \times 2 \mathrm{~mm} \times 4 \mathrm{~mm}$ (Phenomenex). The mobile phase was composed of two solutions: A (ammonium formate $-5 \mathrm{mmol} / \mathrm{L}$ ) and B (methanol) in a gradient which started with $80 \%$ of A and $20 \%$ of B. From 0 to $2.5 \mathrm{~min}$, the concentration of B was raised to $95 \%$ and left for $2.5 \mathrm{~min}$. Finally, after
0.2 min, the B concentration was decreased to $20 \%$ and left for $9 \mathrm{~min}$. The flow rate was $0.4 \mathrm{~mL} / \mathrm{min}$, the column operated at $40^{\circ} \mathrm{C}$, and the ions were monitored in MRM mode (Table 1).

Hydrolysis. Nitrofurans and their metabolites were prepared using the same method as previously described, with some modifications (13). A $2.0 \pm 0.05 \mathrm{~g}$ portion of each sample was transferred to centrifuge tubes. The samples were submitted to hydrolysis and derivatisation processes by adding internal standard mixture (1,2-(15N2, 13C) SEM, AMOZ-d5, (3C13) AHD, and AOZ-d4), $10 \mathrm{~mL}$ of the $0.2 \mathrm{~mol} / \mathrm{L}$ hydrochloric acid, and $240 \mu \mathrm{L}$ of $2-\mathrm{NBA}(10 \mathrm{mg} / \mathrm{mL}$ in methanol). The samples were capped securely in the centrifuge tubes and vortexed for $30 \mathrm{~s}$, then placed in a water bath at $40 \pm 3^{\circ} \mathrm{C}$ and incubated overnight. After the incubation process, the samples were removed from the water bath and cooled down to room temperature. The $\mathrm{pH}$-value of about 7.0 was adjusted by the addition of $10 \mathrm{~mL}$ of $0.2 \mathrm{~mol} / \mathrm{L}$ di-potassium hydrogen orthophosphate solution and $800 \mu \mathrm{L}$ of $1 \mathrm{~mol} / \mathrm{L}$ ammonia solution. The samples were centrifuged at 4,500 $\times \mathrm{g}$ for $15 \mathrm{~min}$ and transferred to the SDB-L cartridges.

Cleanup. SPE cartridges were placed on a vacuum manifold and the cartridges were sequentially conditioned with $3 \mathrm{~mL}$ of ethyl acetate, $3 \mathrm{~mL}$ of methanol, and $5 \mathrm{~mL}$ of water. A small portion $(0.5 \mathrm{~mL})$ of water was left on the cartridges until the application of the sample extracts. The latter were passed through the SDB-L cartridges, washed with $5 \mathrm{~mL}$ of water and $5 \mathrm{~mL}$ of hexane, and eluted with ethyl acetate. The eluates were vortexed for $10 \mathrm{~s}$ and then evaporated to dryness on a heating block at $40^{\circ} \mathrm{C}$ under a gentle stream of nitrogen. The residues were dissolved in $200 \mu \mathrm{L}$ of $60 \%$ methanol solution in water and filtered through Nanosep MF $0.22 \mu \mathrm{m}$ filters before being injected into the LC column.

\section{Results}

The procedure was validated according to the Commission Decision of 2002/657/EC (4). The analysis of 20 blank samples for each of the matrices did not reveal any interference. The criteria concerning relative retention time of the analytes corresponded to those of the calibration solution at a tolerance of $\pm 2.5 \%$.

Table 1. Precursor ions and product ion transitions of nitrofuran metabolites and internal standards - mass spectrometry parameters

\begin{tabular}{|c|c|c|c|c|}
\hline Analyte & $\begin{array}{l}\text { Precursor } \\
\text { ion }(\mathrm{m} / \mathrm{z})\end{array}$ & $\begin{array}{l}\text { Ion } \\
\text { transition }\end{array}$ & $\begin{array}{l}\text { Declustering } \\
\text { potential }\end{array}$ & $\begin{array}{l}\text { Collision } \\
\text { energy }(\mathrm{eV})\end{array}$ \\
\hline \multirow{2}{*}{$\mathrm{AOZ}$} & \multirow{2}{*}{235.95} & 134.0 & \multirow{2}{*}{116} & 15 \\
\hline & & 104.0 & & 29 \\
\hline \multirow{2}{*}{ AMOZ } & \multirow{2}{*}{335.00} & 291.0 & \multirow{2}{*}{71} & 16 \\
\hline & & 262.1 & & 26 \\
\hline \multirow{2}{*}{ SEM } & \multirow{2}{*}{209.00} & 166.0 & \multirow{2}{*}{96} & 13 \\
\hline & & 192.0 & & 15 \\
\hline \multirow{2}{*}{ AHD } & \multirow{2}{*}{249.00} & 134.0 & \multirow{2}{*}{126} & 15 \\
\hline & & 104.0 & & 27 \\
\hline AOZ-D4 (IS) & 239.95 & 134.0 & 136 & 17 \\
\hline AMOZ-D5 (IS) & 340.00 & 296.1 & 106 & 15 \\
\hline SEM-C $_{13}, 2 \mathrm{~N}_{15}$ (IS) & 212.00 & 167.9 & 86 & 13 \\
\hline
\end{tabular}


Table 2. Validation report for nitrofuran metabolites

\begin{tabular}{|c|c|c|c|c|c|c|c|}
\hline Matrix & $\begin{array}{l}\text { Repeatability } \\
\quad\left(\mathrm{RSD}_{\mathrm{r}}, \%\right)\end{array}$ & $\begin{array}{l}\text { Within-lab } \\
\text { reproducibility } \\
\left(\mathrm{RSD}_{\mathrm{wR}} \%\right)\end{array}$ & $\begin{array}{c}\mathrm{CC} \alpha \\
\left(\mu \mathrm{g} \mathrm{kg}^{-1}\right)\end{array}$ & $\begin{array}{c}\mathrm{CC} \beta \\
\left(\mu \mathrm{g} \mathrm{kg}^{-1}\right)\end{array}$ & Apparent recovery $(\%)$ & $\begin{array}{c}\text { Matrix } \\
\text { effect }(\%)\end{array}$ & $\begin{array}{c}\text { Expanded } \\
\text { uncertainty } \\
\left(\mu \mathrm{g} \mathrm{kg}^{-1}\right)\end{array}$ \\
\hline \multicolumn{8}{|c|}{$\mathrm{AOZ}$} \\
\hline feed water & $4.4 \pm 3.4$ & $5.6 \pm 4.1$ & 0.50 & 0.52 & $104.5 \pm 2.8$ & $4.0 \pm 1.9 \%$ & $1.0 \pm 0.14$ \\
\hline feed & $4.9 \pm 4.4$ & $6.6 \pm 4.3$ & 0.50 & 0.54 & $103.5 \pm 6.8$ & $6.1 \pm 2.9 \%$ & $1.0 \pm 0.24$ \\
\hline urine & $5.0 \pm 3.7$ & $6.3 \pm 4.4$ & 0.50 & 0.56 & $104.0 \pm 4.2$ & $6.0 \pm 2.7 \%$ & $1.0 \pm 0.2$ \\
\hline plasma & $3.1 \pm 3.6$ & $5.7 \pm 3.2$ & 0.50 & 0.52 & $98.0 \pm 3.8$ & $4.5 \pm 3.5 \%$ & $1.0 \pm 0.23$ \\
\hline muscle & $2.9 \pm 4.5$ & $4.5 \pm 3.6$ & 0.50 & 0.54 & $103.1 \pm 4.2$ & $5.4 \pm 5.5 \%$ & $1.0 \pm 0.18$ \\
\hline eggs & $7.4 \pm 6.1$ & $10.7 \pm 6.5$ & 0.50 & 0.53 & $97.0 \pm 0.3$ & $7.0 \pm 2.5 \%$ & $1.0 \pm 0.25$ \\
\hline milk & $3.2 \pm 3.8$ & $4.8 \pm 4.4$ & 0.50 & 0.54 & $96.0 \pm 4.9$ & $6.4 \pm 4.3 \%$ & $1.0 \pm 0.18$ \\
\hline honey & $6.1 \pm 3.9$ & $8.7 \pm 5.7$ & 0.50 & 0.53 & $98.7 \pm 6.3$ & $7.3 \pm 5.5 \%$ & $1.0 \pm 0.28$ \\
\hline \multicolumn{8}{|c|}{ AMOZ } \\
\hline feed water & $4.1 \pm 3.4$ & $6.6 \pm 3.1$ & 0.50 & 0.53 & $89.5 \pm 3.8$ & $4.0 \pm 2.0 \%$ & $1.0 \pm 0.18$ \\
\hline feed & $5.1 \pm 5.1$ & $5.3 \pm 3.4$ & 0.50 & 0.54 & $96.5 \pm 6.8$ & $6.3 \pm 4.0 \%$ & $1.0 \pm 0.26$ \\
\hline urine & $6.2 \pm 3.9$ & $7.3 \pm 4.1$ & 0.50 & 0.53 & $103.0 \pm 4.1$ & $6.3 \pm 5.2 \%$ & $1.0 \pm 0.15$ \\
\hline plasma & $3.6 \pm 3.9$ & $4.4 \pm 4.2$ & 0.50 & 0.53 & $95.0 \pm 4.5$ & $4.5 \pm 5.5 \%$ & $1.0 \pm 0.23$ \\
\hline muscle & $5.9 \pm 3.5$ & $6.4 \pm 3.6$ & 0.50 & 0.52 & $106.2 \pm 4.1$ & $5.3 \pm 3.6 \%$ & $1.0 \pm 0.16$ \\
\hline eggs & $5.4 \pm 4.2$ & $5.7 \pm 6.5$ & 0.50 & 0.53 & $97.2 \pm 5.3$ & $5.0 \pm 4.5 \%$ & $1.0 \pm 0.25$ \\
\hline milk & $4.2 \pm 3.9$ & $5.8 \pm 4.4$ & 0.50 & 0.52 & $105.2 \pm 3.9$ & $4.0 \pm 4.3 \%$ & $1.0 \pm 0.16$ \\
\hline honey & $5.9 \pm 4.8$ & $7.7 \pm 4.7$ & 0.50 & 0.53 & $95.7 \pm 5.3$ & $8.0 \pm 4.5 \%$ & $1.0 \pm 0.28$ \\
\hline \multicolumn{8}{|c|}{ SEM } \\
\hline feed water & $4.2 \pm 2.4$ & $8.4 \pm 4.1$ & 0.50 & 0.54 & $88.9 \pm 3.8$ & $3.0 \pm 1.0 \%$ & $1.0 \pm 0.19$ \\
\hline feed & $9.4 \pm 5.4$ & $8.4 \pm 5.2$ & 0.50 & 0.55 & $93.3 \pm 5.6$ & $6.3 \pm 5.5 \%$ & $1.0 \pm 0.35$ \\
\hline urine & $8.6 \pm 4.6$ & $8.4 \pm 4.3$ & 0.50 & 0.53 & $102.0 \pm 6.3$ & $6.3 \pm 5.1 \%$ & $1.0 \pm 0.25$ \\
\hline plasma & $4.1 \pm 3.9$ & $5.7 \pm 4.6$ & 0.50 & 0.53 & $92.0 \pm 4.3$ & $6.5 \pm 4.5 \%$ & $1.0 \pm 0.24$ \\
\hline muscle & $3.9 \pm 3.5$ & $5.4 \pm 4.6$ & 0.50 & 0.54 & $107.3 \pm 5.1$ & $5.3 \pm 5.2 \%$ & $1.0 \pm 0.26$ \\
\hline eggs & $7.4 \pm 6.1$ & $10.6 \pm 6.8$ & 0.50 & 0.55 & $97.0 \pm 5.3$ & $9.0 \pm 4.5 \%$ & $1.0 \pm 0.25$ \\
\hline milk & $5.1 \pm 3.2$ & $6.8 \pm 5.4$ & 0.50 & 0.54 & $95.0 \pm 3.9$ & $7.0 \pm 3.5 \%$ & $1.0 \pm 0.26$ \\
\hline honey & $7.0 \pm 5.8$ & $8.4 \pm 5.7$ & 0.50 & 0.55 & $95.7 \pm 6.3$ & $10.0 \pm 4.6 \%$ & $1.0 \pm 0.31$ \\
\hline \multicolumn{8}{|c|}{ AHD } \\
\hline feed water & $4.9 \pm 3.4$ & $7.4 \pm 4.1$ & 0.50 & 0.54 & $100.5 \pm 2.8$ & $5.2 \pm 2.0 \%$ & $1.0 \pm 0.23$ \\
\hline feed & $5.2 \pm 3.7$ & $8.4 \pm 6.4$ & 0.50 & 0.54 & $94.9 \pm 6.8$ & $5.0 \pm 4.3 \%$ & $1.0 \pm 0.32$ \\
\hline urine & $8.2 \pm 5.7$ & $7.5 \pm 5.5$ & 0.50 & 0.52 & $106.2 \pm 53$ & $6.3 \pm 4.6 \%$ & $1.0 \pm 0.25$ \\
\hline plasma & $4.3 \pm 3.4$ & $4.3 \pm 3.9$ & 0.50 & 0.53 & $95.0 \pm 5.8$ & $6.7 \pm 4.7 \%$ & $1.0 \pm 0.28$ \\
\hline muscle & $3.9 \pm 3.2$ & $4.4 \pm 3.9$ & 0.50 & 0.53 & $102.1 \pm 4.3$ & $5.3 \pm 5.5 \%$ & $1.0 \pm 0.23$ \\
\hline eggs & $6.3 \pm 5.2$ & $8.7 \pm 4.5$ & 0.50 & 0.54 & $94.3 \pm 5.3$ & $4.0 \pm 5.5 \%$ & $1.0 \pm 0.25$ \\
\hline milk & $5.1 \pm 3.3$ & $6.8 \pm 5.4$ & 0.50 & 0.53 & $95.0 \pm 6.9$ & $5.2 \pm 4.3 \%$ & $1.0 \pm 0.28$ \\
\hline honey & $7.3 \pm 4.3$ & $8.1 \pm 5.1$ & 0.50 & 0.55 & $93.4 \pm 7.3$ & $10.2 \pm 5.5 \%$ & $1.0 \pm 0.32$ \\
\hline
\end{tabular}

A linearity $\left(\mathrm{R}^{2}\right)$ for all concentration levels $\left(0.50-10.0 \mu \mathrm{g} \mathrm{kg}^{-1}\right)$ was obtained, within the range of 0.990-0.998. The apparent recoveries for all concentration levels $\left(0.50-10.0 \mu \mathrm{g} \mathrm{kg}^{-1}\right)$ were in the range of $88.9 \%$ to $107.3 \%$ with a repeatability of less than $9.4 \% \quad(2.9 \%-9.4 \%)$, and within-laboratory reproducibility below $10.7 \% \quad(4.4 \%-10.7 \%)$. The expanded uncertainty was calculated at the $1.0 \mu \mathrm{g} \mathrm{kg}^{-1}$ concentration level applying a coverage factor of 2 , which provided a level of confidence of approximately $95 \%$. The calculated ion suppression of the matrix effects for nitrofuran metabolites in all matrices did not exceed $15 \%$. The decision limit $(\mathrm{CC} \alpha)$ and the detection capability $(\mathrm{CC} \beta)$ values were also determined and are presented in Table 2. The individual stock solutions stored at $<-18^{\circ} \mathrm{C}$ were stable for six months. The stability of the stock solutions stored at $6^{\circ} \mathrm{C}$ was six months, and working solutions were stable for three months. The stability of extracts for each of the analysed matrices has been estimated at least one week at $<-18^{\circ} \mathrm{C}$.

\section{Discussion}

To the best of our knowledge, the current method is the first published method for determination of nitrofurans and nitrofuran metabolites using UHPLMS/MS in a single analytical procedure. Based on our earlier experience (13) we intended to use positive ionisation with the ions presented in Table 1 , and the following parameters were optimised by direct flow infusion: source temperature, desolvation gas temperature, desolvation gas, capillary voltage, cone voltage, and collision energy. For all studied analytes one precursor ion and two product ions were selected. Separation of nitrofuran metabolites is generally performed by LC using reversed-phase $\mathrm{C} 18$ columns with a mixture of water and acetonitrile, water buffer, or methanol as the mobile phase $(8,9,13)$. Since in our previously described method the time of analysis was about $20 \mathrm{~min}$ (13), we decided to use a shorter column with $\mathrm{C} 8$ reversed phase. The composition of the mobile 
phase in the previously described method gave a symmetrical peak shape and minimised any matrix effect (13), and this decided us on using this mobile phase (5 $\mathrm{mM}$ ammonium formate, $\mathrm{pH} 4.5$; methanol), but with gradient modification. Example chromatograms of honey (blank and sample fortified with $1.0 \mu \mathrm{g} \mathrm{kg}^{-1}$ ) are shown in Fig. 1.

The main problem in the determination of nitrofurans in feed and feed water and nitrofuran metabolites in food of animal origin is that nitrofurans have low molecular weights and fast metabolism. Another difficulty in determining nitrofurans is their instability, because these compounds are extremely sensitive to daylight $(8,10,11,14)$. To solve these problems we added hydrolysis and derivatisation steps. The latter step increases the molecular weight, thus leads to a significantly increased sensitivity of the method. Thus we decided to build on the method which had previously been developed for the determination of metabolites of nitrofurans in eggs $(3,7,10,13)$. In order to prove the conversion of nitrofurans to nitrofuran metabolites, we developed a method to verify the presence of the parent compounds after the hydrolysis step. The tests were performed at a concentration of $10 \mu \mathrm{g} \mathrm{kg}^{-1}$ to completely exclude the presence of parent compounds. The experiment demonstrated that furaltadone, nitrofurantoin and nitrofurazone were completely converted into their metabolites, while furazolidone was an exception, being 96\% converted into its metabolite (Fig. 2). Our results clearly prove that this method can be used to determine the residues of both nitrofurans and their metabolites.

The proposed method was used to analyse the nitrofuran metabolites and nitrofurans in water, feed water, milk, honey, urine, muscle, and egg samples within the official control programme in Poland. Over the last three years, nine honey samples containing furazolidone (AOZ) have been found: the lowest concentration was $0.8 \mu \mathrm{g} \mathrm{kg}^{-1}$ and the highest $12.36 \mu \mathrm{g} \mathrm{kg}^{-1}$. These results showed that this method is important and useful in qualitative and quantitative routine analysis for nitrofurans and nitrofuran metabolites.

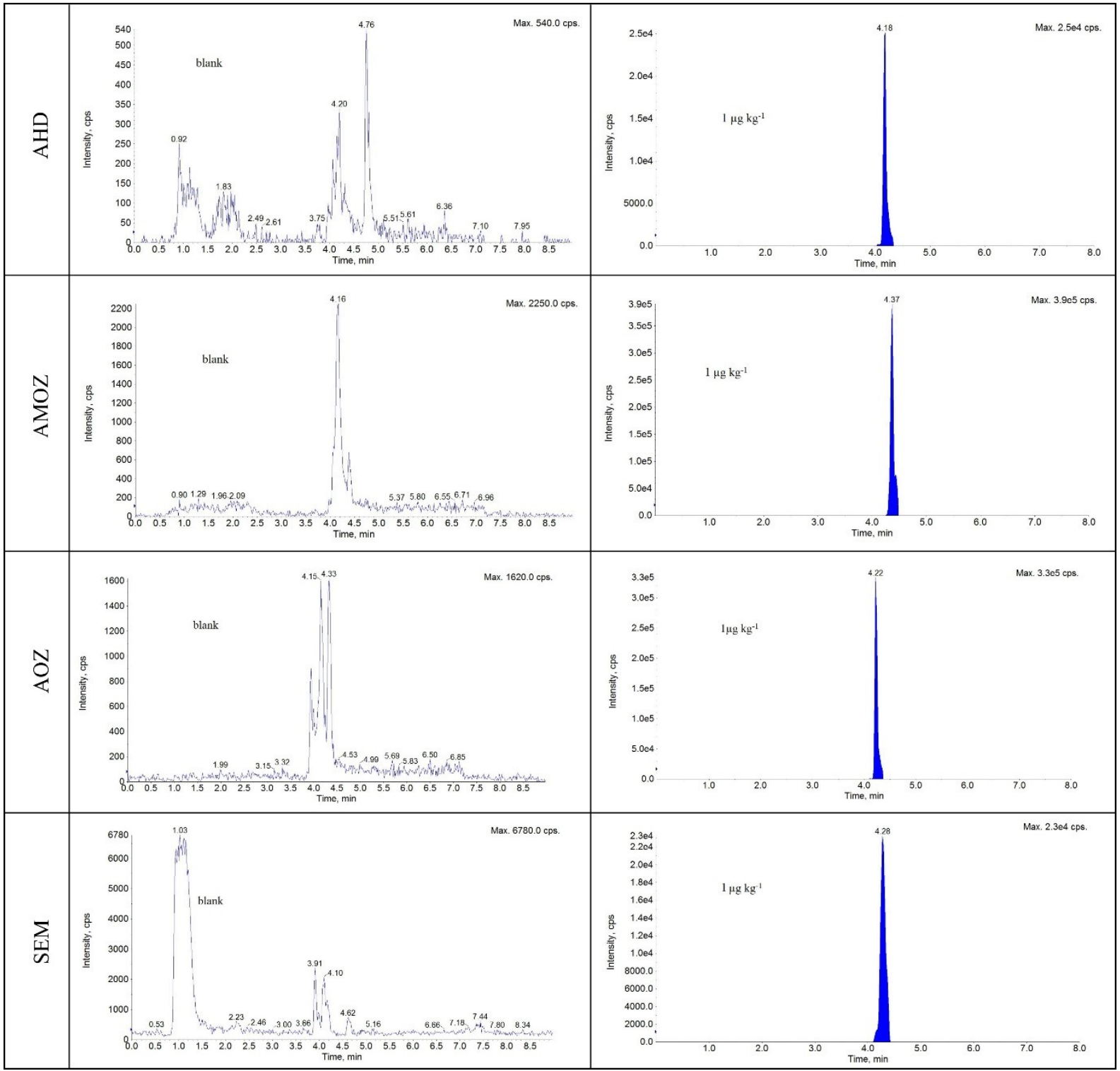

Fig. 1. Chromatograms of blank and spiked honey matrices with nitrofurans $\left(1.0 \mu \mathrm{g} \mathrm{kg}^{-1}\right)$ 


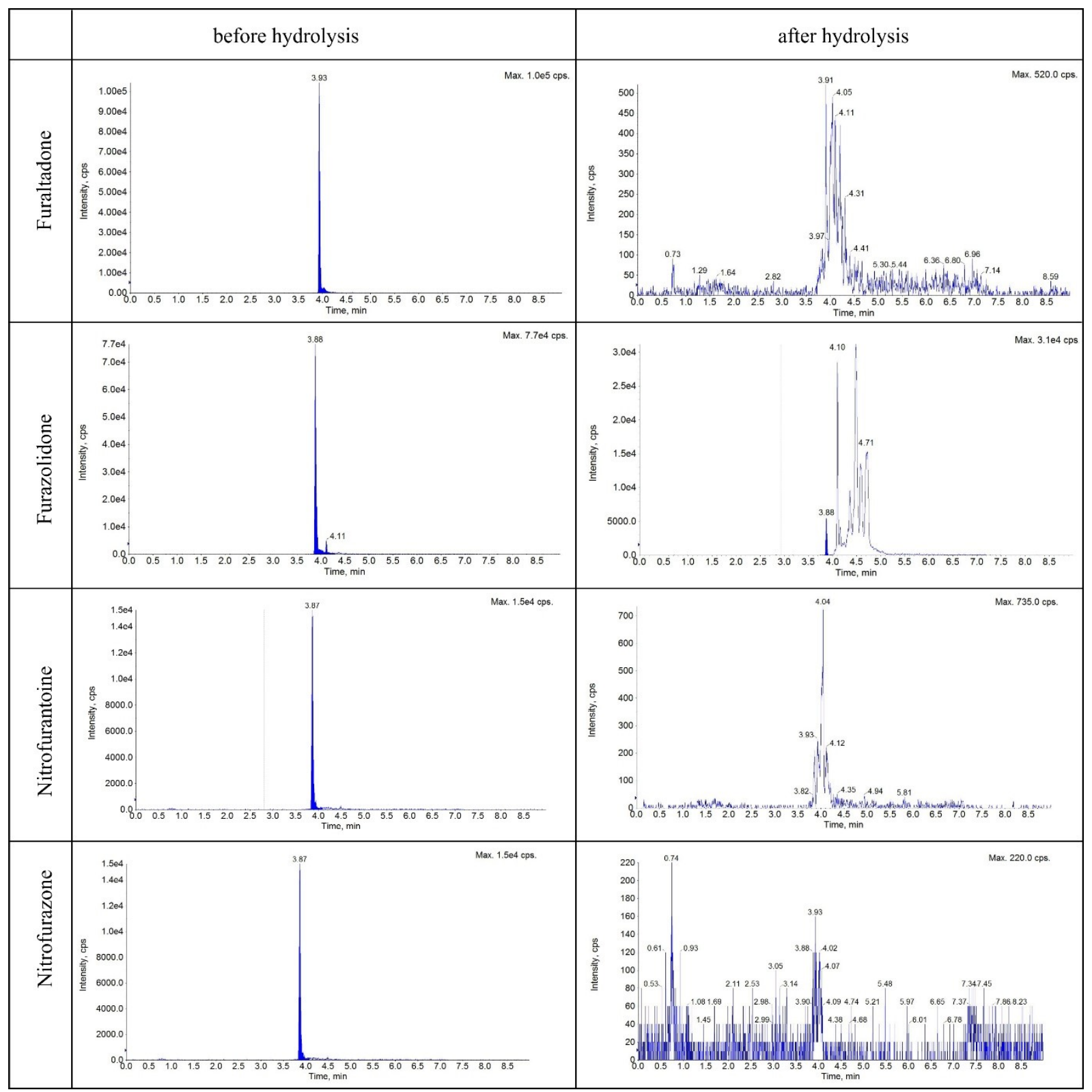

Fig. 2. Chromatograms of nitrofurans, before and after hydrolysis $\left(10.0 \mu \mathrm{g} \mathrm{kg}^{-1}\right)$

The procedure presented in the current article is able to detect nitrofurans and nitrofuran metabolites in various matrices like feed, feed water, urine, plasma, muscle, eggs, milk, and honey in one method, and its validation parameters show that it meets the European Union criteria. The method is now used for the effective routine analysis of nitrofurans and their metabolites in the National Monitoring Plan in Poland.

Conflict of Interests Statement: The authors declare that there is no conflict of interests regarding the publication of this article.

Financial Disclosure Statement: This work was funded by KNOW (Leading National Research Centre) Scientific Consortium "Healthy Animal - Safe Food", decision of the Ministry of Science and Higher Education No. 05-1/KNOW2/2015.
Animal Rights Statement: None required.

\section{References}

1. Ardsoongnearn C., Boonbanlu O., Kittijaruwattana S., Suntornsuk L.: Liquid chromatography and ion trap mass spectrometry for simultaneous and multiclass analysis of antimicrobial residues in feed water. J Chromatogr B Analyt Technol Biomed Life Sci 2014, 945-946, 31-38.

2. Barbosa J., Moura S., Barbosa R., Ramos F., da Silveira M.I.N.: Determination of nitrofurans in animal feeds by liquid chromatography-UV photodiode array detection and liquid chromatography-ionspray tandem mass spectrometry. Anal Chim Acta 2007, 586, 359-365.

3. Bock C., Stachel C., Gowik P.: Validation of a confirmatory method for the determination of residues of four nitrofurans in egg by liquid chromatography-tandem mass spectrometry with the software InterVal. Anal Chim Acta 2007, 586, 348-358.

4. Commission Decision 2002/657/EC of 12 August 2002 implementing Council Directive 96/23/EC concerning the 
performance of analytical methods and the interpretation of results. OJ L 221, 17.8.2002, 8-36.

5. Council Directive of 29 April 1996 on measures to monitor certain substances and residues thereof in live animals and animal products and repealing Directives 85/358/EEC and 86/469/EEC and Decisions 89/187/ EEC and 91/664/EEC. Off J Eur Commun 1996, L125, 10-32.

6. Council Regulation (EEC) of 26 June 1990 laying down a Community procedure for the establishment of maximum residue limits of veterinary medicinal products in foodstuffs of animal origin, Brussels, Belgium. Off J Eur Commun 1990, L224, $1-124$.

7. De La Calle M.B.: Determination of semicarbazide in fresh egg and whole egg powder by liquid chromatography/tandem mass spectrometry: interlaboratory validation study. J AOAC Int 2006, 89, 1664-1671.

8. Fernando R., Munasinghe D.M.S., Gunasena A.R.C., Abeynayake P.: Determination of nitrofuran metabolites in shrimp muscle by liquid chromatography-photo diode array detection. Food Control 2017, 72, 300-305.

9. Leitner A., Zöllner P., Lindner W.: Determination of the metabolites of nitrofuran antibiotics in animal tissue by high- performance liquid chromatography-tandem mass spectrometry. J Chromatogr A 2001, 939, 49-58.

10. McCraken R.J., Spence D.E., Floyd S.D., Kennedy D.G.: Evaluation of the residues of furazolidone and its metabolite, 3-amino-2-oxazolidone (AOZ), in eggs. Food Addit Contam 2001, 18, 954-961.

11. Pietruszka K., Olejnik M., Sell B.: Development and validation of a liquid chromatography method for the determination of nitrofurans in water. Bull Vet Inst Pulawy 2007, 51, 267-270.

12. RASFF - the Rapid Alert System for Food and Feed. https://webgate.ec.europa.eu/rasff-window/portal/?event=search ResultList.

13. Śniegocki T., Posyniak A., Żmudzki J.: Determination of nitrofuran metabolite residues in eggs by liquid chromatographymass spectrometry. Bull Vet Inst Pulawy 2008, 52, 421-425.

14. Viñas P., Campillo N., Carrasco L., Hernández-Córdoba M.: Analysis of nitrofuran residues in animal feed using liquid chromatography and photodiode-array detection. Chromatographia 2006, 65, 85-89. 